\title{
CENTRAL INTEGRATION OF DEVELOPING NERVE TRACTS FROM SUPERNUMERARY GRAFTED EYES AND BRAIN IN THE FROG ${ }^{1}$
}

\author{
EMERSON HIBBARD ${ }^{2}$ \\ Department of Zoology, University of Michigan, Ann Arbor, Michigan \\ FIFTEEN FIGURES
}

One of the unsolved mysteries of neurogenesis is how growing nerve fibers become oriented within the brain and find their way to their proper destinations. Due to the fact that the optic nerve is a correlative brain tract, relationships established between the retina of the eye and the terminals of its optic nerve within the optic lobes of the brain are significant for analyzing some of the features of intracentral organization of fiber tracts. I shall focus on two particular aspects of the general problems under consideration, namely: (1) To what extent, if any, can the neurons of supernumerary or atypically located transplants of eyes or brain establish functional synaptic connections with central nuclei of the host? (2) What morphological effects or behavioral responses result from ingrowth of anomalous optic tracts?

Since 1907, when Harrison settled the controversy over the formation of the axon by proving in tissue culture that the axon was an outgrowth of the nerve cell body, there have been many attempts to analyze experimentally the factors involved in the development and orientation of nerve fibers.

\footnotetext{
${ }^{3}$ Based on a portion of a dissertation submitted in partial fulfillment of the requirements for the degree of Doctor of Philosophy at the University of Michigan. I wish to express special thanks to Dr. Norman E. Kemp who supervised this work, and to Dr. Clement L. Markert whose suggestions led to its inception.

${ }^{2}$ Present address: Institute of Animal Geneties, University of Edinburgh, Edinburgh 9, Scotland.
} 
The uniformity seen in the establishment of nerve patterns made it obvious that something must guide the outgrowing fibers to their destinations. Attempts to explain this phenomenon led to development of several theories of attractions or guiding influences in which chemical, electrical, or mechanical forces were invoked.

The reader is referred to the theories of neurotropism (Cajal, 1898), stimulogenous fibrillation (Bok, '15), neurobiotaxy (Kappers, '17), and the electro-dynamic theory (Burr, '32).

Weiss cast doubt on all of the preceding theories when in 1934 he grew nerve tissue in vitro and found that the protoplasmic outgrowths from nerve cell bodies were unaffected by chemical or electrical agents, but followed the orientation of the ultrastructure within the clot. $\mathrm{He}$ explained growth of fibers between centers of proliferation on the basis of dehydration of their surroundings, which caused tension patterns and realignment of the ultrastructure between them. This had the obvious advantage of allowing for the reciprocal growth of fibers, a difficult thing to explain on the basis of chemical or electrical gradients. He was also able to show in vitro that if the ultrastructure is oriented in such a way as to cross the direction of outgrowth of the fibers, they will be deflected into the new directions; and he suggested that brain layers might similarly redirect growing fibers.

However, it soon became apparent that dependence upon substrate configuration failed to account for many of the features of nerve development because nerve fibers do not grow at random along all pathways available to them. Weiss ('47) accordingly hypothesized a chemical basis of a different sort. Rather than acting as a gradient of chemical diffusion in the milieu, this new guiding element was a biochemical specification of surfaces of both the ultrastructure and the nerve processes, resulting in molecular affinities between them. Weiss ('58) strongly contends that nerve 
orientation is primarily, if not entirely, the result of "selective contact guidance."

In opposition, Burr ('58) has spoken out equally strongly in favor of the electrical-field concept of attraction, claiming to have measured action current potentials in the open air outside nerve fibers, and to have demonstrated the existence of a "quasi-electro-static field." This, he contends, constitutes a set of forces which establishes the pattern and determines the design of the nervous system.

The problem of specificity of neural connections has been investigated almost exclusively in experiments conducted on the peripheral nervous system or involving regeneration of tracts within the central nervous system. Studies of directional outgrowth of nerves to transplanted limbs were first reported by Harrison ('07) more than 50 years ago. He showed that functional activity was not important in the early development of nerve paths, but that their distribution was determined by structures within the limb. Not only does function occur in limbs transplanted to abnormal positions on the body (Nicholas, '33), but the synonymous muscles contract equally and at once ("homologous response," Weiss, '36). Each muscle in the grafted limb was somehow able to impart to the nerves supplying it the information that it was a specific muscle and should contract concurrently with its counterpart in the normal limb. Weiss explained this on the basis of a specifying or modulating effect extending from the muscle to some part of the peripheral nervous system so that the motor neurons to that muscle would then adinit only appropriate motor impulses. Weiss later ('37) pointed out that there was non-selectivity in the establishment of new neuromuscular connections in sectioned peripheral nerves, and therefore the selectivity in homologous response must be of a physiological rather than anatomical nature.

Sense organs such as an eye, olfactory organ, or otic vesicle transplanted to the side of a urodele, in place of a limb rudiment or near an intact one, exert a "directional attrac- 
tion" on outgrowing spinal nerves (Detwilex and van Dyke, '35). These investigators considered this to be due to forces resulting from proliferation within the grafted organ, or to the type of structural orientation previously proposed by Weiss.

Since 1926, when Matthey demonstrated recovery of vision in urodeles after section of the optic nerve, many ingenious and significant experiments have been performed, using regeneration of the optic nerve as a tool for studying (1) selectivity in the systematic reestablishment of terminal connections in the brain and (2) the ability of central reintegration or reorganization to correct maladaptive visuomotor coordination (especially by Stone, '30, '42, '44, '48, '50; Stone and Zaur, '40; and Sperry, '42, '43a, '43b, '44, '45a, '45b, '45c, '48, '49). These experiments established the fact that regeneration of the optic nerve after inversion of the eye through 180 degrees, or after transposing one or both eyes for the other, resulted in responses of the animals that showed uncorrectible reversal of visual perception, even though such reversal was more of a handicap than total loss of vision. This restoration of vision according to the pattern laid down in the brain before inversion of an eye was explained by Sperry ('43) on the basis of a polarized differentiation of the retina during development, such that optic nerve fibers arising from any point of the retina acquired a specificity for a particular point in the optic tectum of the brain. So specific indeed is the central synapsis that its capacity for restoration is evidently retained during regeneration. Pathways established by original ingrowth of the optic nerve must simplify the route of regenerating axons of the optic nerve as they return to the tectum, but it is remarkable that they apparently make their synapses according to the original polarity of the retina.

In light of the fact that eyes and other sense organs have been transplanted to various sites on the body to study differentiation and induction of associated structures (Lewis, '05, '07 ; King, '05; Uhlenhuth, '12 ; Detwiler, '29; Drago- 
mirow, '33; Twitty, '55; Yntema, '55) and modifications of the central nervous system and spinal nerves (Burr, '16, '32; May, '27; Detwiler and van Dyke, '35), it is surprising' that there have apparently been no previous attempts to determine whether such structures could establish functional neural connections with the brain of the host. The development of such connections from supernumerary sense organs during neurogenesis would imply highly selective growth of nerve fibers toward brain centers, efficiency in traversing unfamiliar territory within the brain of the host without being deflected from their course to a normal destination, and an ability to compete with normal fibers in making synaptic connections with central neurons.

\section{MATERIALS AND METHODS}

In these experiments, a supernumerary eye was grafted homoplastically into the roof of the brain (fig. 1). Two embryos at Shumway stage 17, early tailbud, were removed from their jelly capsules for each operation and placed in a flamed, wax-bottom operating dish containing standard Holtfreter's solution. A depression of a size and shape to accommodate a single embryo was then fashioned in the wax with a glass molding rod.

The head of the donor was severed from the body, halved, and a diamond-shaped area large enough to contain the entire eye rudiment was removed from one side, using for this purpose a sterile micro-dissecting knife (Burch, '42) fashioned from a sliver of razor-blade soldered into the eye end of a needle.

The head of the host was then prepared by making an incision through the roof of the brain in the midline of the mesencephalon and diencephalon. The eye rudiment, with in most cases a small part of the brain wall attached to it by the optic stalk, was moved into the incision. The embryo was then pushed into the wax depression and covered with a narrow cover-glass bridge to hold the graft in place. It was 
left in the depression for from 45 minutes to two hours, after which the wax was cut away and the embryo was carefully removed from the depression by means of a hair-loop. It was allowed to lie on the surface of the wax in the operating dish until the ectoderm surrounding the wound had partially healed to that of the graft, usually in about two hours. Then it was carefully transferred by pipette to a finger-bowl containing $1 / 5$ Holtfreter's solution. After remaining overnight in this solution, the embryo was moved into another fingerbowl containing aerated tap water.

Those larvae which readily could be identified by the appearance of their grafts were put into an aquarium or large enamel pan and fed boiled, strained spinach and lettuce, minced frog liver, and tropical fish food. They were maintained on this diet until they were fixed for sectioning or began metamorphosis. The latter were put into an aquarium which was tilted so that they could easily crawl from the water onto the moist slate bottom.

For testing optokinetic response, an apparatus similar to that described by Sperry ('44) was used. This consisted of a cylinder $12.5 \mathrm{~cm}$ in diameter, with vertical black and white stripes $2.5 \mathrm{~cm}$ wide painted on its inner surface, mounted on a power stirring tool. The pattern on the inner side of the cylinder was broken by filling in one of the white stripes with black and putting horizontal black stripes across another white stripe to provide fixation points in the visual field. The tool was connected to a rheostat for adjusting the current and the speed of rotation of the drum. By inverting the tool and cylinder, the direction of rotation could be reversed. The tadpole to be tested was placed in a jar which was either suspended in the center of the cylinder, or set on a ringstand under the inverted apparatus. In either case, the support for the jar was on a heavy table separated from that on which the apparatus was based, in order to minimize the effect of vibrations. The tadpoles responded to the moving visual field by turning in the direction of rotation of the cylinder. 
For each series of tests, the drum was alternately revolved for one minute and stopped for one minute, over a 10-minute period of time. A half-hour rest period was then permitted, following which the tests were repeated. A total of $40 \mathrm{~min}$ utes of testing was used for each condition tested. Running the motor of the tool detached from the drum resulted in no appreciable increase of activity of either the controls or experimental animals.

At various times, from 8 to 140 days following the operation, tadpoles or frogs were fixed for several days in Bouin's solution, decalcified overnight in 5\% formic acid in $70 \%$ alcohol, dehydrated in alcohols and amyl acetate, and rinsed in toluol. They were infiltrated and embedded in paraffin, sectioned serially at 10 microns, and placed on glass slides for staining. Bodian's protargol method for staining nerve fibers was used. A few specimens were stained with Silver's rapid-silver method, with hematoxylin and eosin, or with both.

Graphic reconstructions of eyes and brains were made by offsetting the horizontal and vertical axes of outline drawings of serial sections on millimeter graph paper.

\section{RESULTS}

One-hundred and eighty operations of this type were performed. In 39 cases the implanted eye failed to heal in place, or the embryo died following the operation. Of the 141 animals remaining, 54 were discarded because the eyes were imperfectly formed. These eyes ranged from nearly indistinguishable but darkly pigmented knobs on the head to movable globes which were apparently complete except for a lens. They were all considerably smaller than the normal eyes of the host. In a few cases an incomplete optic rudiment may have been implanted, but the main reason for imperfect formation seems to be that the eye fields were removed from a very early tailbud stage and grafted into embryos of a later stage. 
Twenty-six of the remaining specimens were selected for serial sectioning. Of these, 23 formed extensive neural connections between the grafted brain and the brain of the host. Fusion of the implanted and host brains occurred at various points from the posterior telencephalon to the region of the roots of cranial nerves IX and $X$ in the medulla. In 4 instances, although the implanted brain was well incorporated into the host's brain, no optic nerve had formed between the implanted eye and the corresponding portion of implanted brain.

Nieuwkoop ('52), in a study of the organization of the central nervous system, grafted bits of presumptive epidermis homoplastically to the dorsal side of embryos ranging in age from the early gastrula to middle neurula. He claimed that grafts implanted into prospective tel- and diencephalon regions were always found later in the roof of the brain without any connection to the floor of the nervous system. Although in my material there does seem to be a marked tendency for symmetrization of the implant and the host's brain, resulting in connections being made primarily with the roof of the diencephalon (figs. 5 and 6 ) my results refute Nieuwkoop's contention that connections are never made with the floor of this region. Six of the 26 sectioned specimens under discussion had large columns of nerve fibers crossing the ventricle from the implanted brain to the floor or lower wall of the diencephalon of the host. In one of these, the column of fibers entered the floor of the optic recess immediately in front of the optic chiasma, while in two others it went directly to the optic chiasma.

\section{Functional motor innervation of transplanted eyes}

Synchronous eye movements

In two specimens the grafted eye moved synchronously with the normal right eye of their host. One host died before it could be fixed for sectioning, but the other, tadpole IX, lived for several weeks. In this specimen, a column of nerve 
fibers crossed the third ventricle from the grafted brain to the optic chiasma of the host. The implanted eye underwent pronounced quivering movements which were synchronous with similar movements of the right eye of the host. These movements corresponded not only in time but also in direction and extent of rotation with those of the normal eye. Occasionally the implanted eye moved by itself. This was apparently a spontaneous backward type of movement, with the eye turning through an angle of about 30 degrees.

Tadpole IX was maintained in an aquarium for three months before fixation. During that time it was extremely active. When sacrificed, it was healthy and vigorous but it was only about $3 / 4$ the size of normal controls of the same age. Since it was developing hind-limb buds and thus had started to metamorphose, its pituitary and thyroid glands evidently were functioning well. Possibly its small size was due to its hyperactivity, the exact cause of which was not determined.

In studying sections of this specimen, it was found that a large optic nerve left the retina of the implanted eye, partially bypassed the portion of implanted brain, and made a column directly through the ventricle of the diencephalon to the optic chiasma of the host. Here the fibers mingled with the fibers of incoming normal optic nerves (fig. 2).

Since the synchronous movements of implanted and normal eyes indicated some sort of neuromotor connection of the implant with the brain of the host, the nerves to the eye muscles of the implant were traced back from the muscles to their origins but were found to have originated in the implanted brain. The outer layer of the optic tectum of the grafted brain appeared to have undergone hypertrophy, and there was a second column of fibers joining the floor of the midbrain of the graft with that of the host. As may be seen in figure 2, nerve fibers of both optic nerves of the host ascended the anterior column from the chiasma to the implanted brain and thence to the tectum of the implant. Whether the quivering movement of the eye results from a 
sensory-motor are of visual origin or from proprioceptive stimuli is uncertain; but the morphological evidence leaves no doubt that the synchronous movements observed in tadpole IX were the result of integrated neuronal connections between the brains of both implant and host. This specimen was not tested for optokinetic response.

Vestibular reflex

Implanted eyes of two tadpoles demonstrated a vestibular reflex along with the normal eyes when the tadpoles were rocked. In both tadpoles, the implanted eyes definitely responded to movement above them or to passing shadows by twisting in their sockets, although the response was usually independent of movement of the normal eyes of the host. In specimen VR-1, the implanted eye twisted counterclockwise through an angle of approximately 40 degrees; in VR-2 it twisted clockwise through an angle of about 25 degrees.

Tadpole VR-1. The implanted eye of this specimen stood prominently on top of the head in line with the normal left and right eyes of the host, and a small proboscis consisting of an external naris and a lip without cornified teeth projected forward from it. There was an occasional twitching of the proboscis. The implanted eye quivered most of the time, but the normal eyes remained quiet. When swimming, the tadpole revolved continuously counterclockwise in a corkscrew motion around its longitudinal axis. A description of a similar corkscrew swimming motion in larvae lacking one ear vesicle has been given by Detwiler ('36). No disturbance of auditory vesicles or nerves could be found in tadpole VR-1.

Serial sections revealed a well developed optic nerve from the eye of the implant to its diencephalon and extensive arborization of fibers between the implant and the host's brain, from the region of the superior telencephalic commissure and anterior choroid plexus through the thalamic region to the mesencephalon. There existed a bilateral symmetry between the implanted brain parts and the left half of the host's brain. Behind the diencephalon the optic lobe and 
torus semicircularis of the right side of the host's brain became separated from the remainder of the brain and rejoined it at the level of the isthmus.

Some tracts entered the posterior portion of the implanted brain from the medulla of the host. These may represent ascending tracts from the vestibular nuclei, although they could not be traced with certainty.

Tadpole VR-2. In specimen VR-2 the relationships between the implanted brain and that of the host were quite different from those observed in the preceding specimen, VR-1. Here the implanted neural tissue composed an almost complete half-brain, possessing even a part of the medulla and the telencephalon. The implanted part of the telencephalon probably included the pallium but lacked the anterior portion of the telencephalon and the olfactory organ. This half-brain remained completely separate from the brain of the host, except for very extensive neuronal connections with both sides of the medulla. On the left side, the connection was with the ventricular wall above the roots of the trigeminal and facial nerves, while on the right it was with the ventricular wall above the root of the auditory nerve (figs. 3 and 4$)$.

Several nerve fibers of the descending tracts of the implanted medulla appear to be directed toward the corresponding tracts of the host, particularly the fasciculus solitarius and the fasciculus longitudinalis medialis. Fibers entering the medulla in the root of the auditory nerve of the host could be seen turning toward the implant. Some of these, vestibular in character, and associated neurons with which they synapse, enter the implant and probably are responsible for the reflex action of the implanted eye.

\section{Functional sensory innervation of transplanted eyes}

Although the specimens described in the previous section gave distinet motor responses to sensory stimuli, the stimuli considered were those provided primarily by neurons of the 
host. In this section we shall deal with motor responses of the host to visual stimulation of the implanted eye.

Of 11 specimens tested for optokinetic response, unequivocal evidence that visual perception by the implanted eye mediated motor activity of the host was obtained in only one, tadpole OR-1. It is here presented in detail.

Within one week following the operation, this specimen revealed definite signs of photophobia, constantly attempting to "bury" the implanted eye under a growth of algae or other cover in the aquarium. When the cover was removed, the tadpole became very restive until it again obtained cover. This tadpole was more lightly pigmented than the normal controls. Within 6 weeks it no longer showed such a marked negative response to light but swam rapidly in counterclockwise circles in open water.

While either resting or when in motion the tadpole assumed a tilted position slightly on its right side, thereby keeping the implanted eye and its own left eye on a horizontal plane with each other. The left eye was held twisted in a clockwise direction on its optical axis, about 50 degrees from the normal horizontal position, as indicated by the black pigmented line across the iris. The spinal column and tail were bent to the left and downward at all times. This flexion, plus the additional weight of the head, apparently displaced the center of mass, causing the head to point somewhat downward (fig. 9). This posture may account for the twist of the left eye. The implanted eye was immovable.

Three series of tests for optokinetic response were carried out on two successive days. Since this tadpole could swim only in counterclockwise circles, the tests were made with counterclockwise rotation of the drum.

For testing the response, the drum was alternately rotated at $20 \mathrm{rpm}$ for one minute and then held motionless for one minute, over a 10 -minute period of time for each test in the series. A half-hour rest period followed each 10-minute test. Four tests were run on the specimen with all three optic nerves intact. During the total 40 -minute test period, the 
tadpole made 271 complete turns while the drum was revolving, and 117 while it was motionless. Thus it made 2.3 times as many revolutions when the drum was in motion as when it was motionless.

The animal was anaesthetized with MS222 at a concentration of 1:8000 and the optic nerves from both normal eyes were cut, leaving only the optic nerve of the implant intact. After a three-hour period of recovery from the operation, another series of tests were run. During a 40-minute total the tadpole made 371 turns with the drum revolving and 183 when it was stopped. The animal was then examined under a dissecting microscope to be certain that the normal nerves had been completely severed. It was found that they had been, but in the process of examination the right eye was accidentally punctured. Another 40-minute series of tests were run, and this time the tadpole made 391 turns with the drum in motion and 156 with it motionless.

These data show that after section of the normal optic nerves, the tadpole had made 2.25 times as many turns with the drum revolving as it made while the drum was motionless. This agrees very well with the increase noted when all the nerves were intact, but it may be seen from these figures that the general hyperactivity of the animal also had increased after section of the normal optic nerves. Further reference to this fact will be made later.

Serial sections of this animal subsequently disclosed a small portion of implanted telencephalon lying over the anterior choroid plexus of the host, a complete half of a diencephalon and mesencephalon very extensively fused with the brain of the host (figs. 5 and 7 ), and a bit of cerebellum and medulla behind the optic lobe.

The diencephalic part of the implant was symmetrically situated in the roof of the normal diencephalon with broad connections of commissural tracts overlying the roof of the ventricle on both sides (fig. 5). There was a marked similarity between migration layers and brain nuclei of the implant and the host. The 4 divisions of the diencephalon-epi- 
thalamus, dorsal and ventral thalamus, and the hypothalamus - were all represented in the implant. The effects produced by commissural connections of the host's diencephalon with both the "dorsal" and "ventral" diencephalic parts of the implant are unknown.

Behind the region of the posterior commissure, the floor of the implanted mesencephalon was broadly connected with the dorsolateral and ventrolateral columns of the right side of the host's midbrain. The optic tectum and torus semicircularis of the implant were so situated as to form a nearly symmetrical mirror image of the right half of the host's brain, thus making an optic ventricle with its normally horizontal axis in a nearly vertical position (fig. 7). The roof of the left side of the host's midbrain was spatially isolated from both the implant and the right side, and was connected to the graft by a thin membrane consisting of a single layer of ependymal cells and the pia mater.

The orientation and symmetry of the implanted brain are of particular interest because the optic rudiment with its attached stalk and portion of brain wall had been removed from the right side of the donor. Therefore one might expect the brain which developed from this fragment to form a right, rather than a left, optic lobe. A regulating influence of either the implanted eye or the host's brain apparently caused a reversal of the original symmetry. Whatever the cause of this reversal, fibers of the grafted optic nerve and tract could be traced to the optic tectum of the implanted brain.

In the extensive arborization of neurons between the tori semicirculares of the implant and host are both ascending and descending tectal tracts. The efferent fibers of the ventral tecto-bulbar tract descend from the implant and join those of the host, and probably terminate around efferent centers of the medulla. Acousticolateral and spinotectal fibers ascend into the caudal and lateral portions of the implanted tectum. The periventricular layers of the tectum are continuous over the fused tori, and commissural fibers con- 
nect the torus semicircularis of the graft with that of the host. The medulla of this tadpole however, appeared to be normal except for the fact that on the right side, which also was the side with which the mesencephalon of the grafted brain had fused, there were two Mauthner's cells, rather than one.

\section{DISCUSSION}

Mauthner's cells are giant coordinating neurons peculiar to fishes and amphibians located at the base of the VIIIth cranial nerve and are involved in controlling flexion of the trunk and tail in swimming (Herrick, '48; Kappers, Huber, and Crosby, '36; Detwiler, '36; Oppenheimer, '41; Green, '47; Stefanelli, '51). In “The Comparative Anatomy of the Nervous System of Vertebrates," Kappers, Huber, and Crosby (op. cit., p. 653) state: "In adult tailless amphibians there is no cell of Mauthner. The evidence is not at hand to enable determining whether or not it is present in the larval stage of the frog." More recently Steffanelli ('51) lists a number of anuran species, not, however, including Rana pipiens, in which Mauthner's cells have been found.

A single pair of Mauthner's cells definitely are present in R. pipiens tadpoles (fig. 10). Though Steffanelli indicates that in anurans they involute at metamorphosis, they apparently are retained for a time following metamorphosis since they may still be found after the tail has been resorbed.

Mauthner's cells are derived from cells of the tegmentum motorium (Steffanelli, '51), and the large size of both their cell body and axon indicates strong functional activity and rapid conduction. Their dendrites can be stimulated through vestibular and lateral line nerves, other elements of the tegmentum motorium, stem fibers and collaterals of the median longitudinal fascicle, and spinobulbar and tectobulbar tracts (Herrick, '14; Kappers, Huber and Crosby, '36; Steffanelli, '51). The giant axons of the Mauthner's cells decussate and descend the entire length of the spinal cord in the median longitudinal fascicle of the opposite side. Although giant 
axons in fishes give off numerous collaterals along their length, those in the frog are relatively smooth. Based on the fact that these axons have connections with intercalary cells as well as motor neurons, Coghill ('36) considered their activity to be inhibitory rather than excitatory; but Detwiler ('36) said they were "... concerned with transmission of impulses requisite for the maintenance of sustained coordinated swimming reflexes." He found that in the absence of these cells the trunk musculature became more easily fatigued following prolonged swimming activity. Leghissa ('41) stated that the Mauthner's cell is a true associative motor center, not a simple intercalary neuron of a reflex arc.

Differentiation of Mauthner's cells probably can be influenced by the presence or absence of associated neurons. Piatt ('47) showed that removal of the ear primordia resulted in failure of about $1 / 3$ of the Mauthner's cells to differentiate. This was confirmed by Detwiler ('47). Greene ('47), on the other hand, showed that a Mauthner cell occasionally developed at or near the entrance of an VIIIth nerve that was made to enter the brain at an abnormal location.

In light of these facts, the differentiation of a supernumerary Mauthner's cell in the experimental animal OR-1 may have resulted from the additional load imposed upon the right side of the medulla by the tectobulbar tracts from the implanted brain. The presence of this additional giant cell, assuming it to be a site of initial motor activity (Beccari, '07; Herrick, '14; Kappers, Huber, and Crosby, '36), may in turn be responsible for the abnormal swimming movements. Two giant axons can be traced in the left median longitudinal fascicle (fig. 11). By increasing the stimulation of the motor neurons of the left side, the consequent exaggeration of contraction of the flexor muscles in the trunk and tail of that side would cause a forced circling of the animal to the left. Since the Mauthner's cell is important in sustained swimming movements, it also may have contributed to the hyperactivity of the experimental animal, both before and after section of the normal optic nerves (fig. 15). 
Another possible explanation of the circling activity of this tadpole is simply that the additional functional eye produced an incongruous effect in the tectal representation of the visual field. Sperry ('48) discussed forced circling activity in various species of teleosts after changing the orientation of their eyes. One species "... turned continuously thereafter around a fixed spot close to the bottom of the aquarium," while another rested on the bottom most of the time but when aroused "... whirled at very high speed in circles of a diameter roughly that of their total length." He mentioned various other peculiar gyrations "... indicating illusory movement of the visual field in other planes."

As was mentioned previously, the dorsoventral axis of the experimental tadpole was tilted to the right so that the implanted eye and the left eye were maintained on a horizontal plane. This simply may have resulted from displacement of the center of gravity by the increased mass of the right side of the brain, or from flexion of the tail to the left and downward. However, since the optic lobe of the implant appears to have formed an harmonious functional unit with the right optic lobe of the host's brain, it may be that the panoramic image projected there may have caused the tadpole to keep the implanted eye and left eye on as nearly a horizontal plane as possible in order to maintain the visual field in that plane.

The general pallor of this tadpole may also have resulted from the abnormal position of the implanted eye. Sperry ('43) found that in newts whose eyeballs had been rotated 180 degrees, leaving the optic nerves intact, there was a dorsoventral reversal of the chromatophoric adaptation. This is apparently mediated partially through optic nerve fibers terminating in the hypothalamus near the chiasma. These presumably influence the endocrine activity of the pituitary. Stoppani ('42) found the eyes to be the most important receptor of stimuli controlling pigmentation changes. He found that in Bufo arenarum, the infundibulum inhibits se- 
cretion of melanotropic hormone and stimulates secretion of adrenaline, causing contraction of melanophores.

Chromatophoric adaptation resulting from changes in light intensity does not, however, provide a good means for testing vision in $R$. pipiens tadpoles, because in them this adaptation is apparently primarily controlled either directly through the skin or by means of an endocrine system involving the pineal organ. Blind and normal tadpoles respond similarly to changes in light intensity, becoming darkly pigmented in bright light and lightly pigmented during a period of dark adaptation.

Specimen OR-1 provides conclusive evidence that nervous integration of grafted and host brain can occur. The integration in this specimen was sufficiently precise to permit functional responses to visual stimuli from the implanted eye. It seems reasonable to assume that the oriented structures encountered by fibers growing from the implant into the host's brain are foreign to these fibers and are different from those normally encountered by the homologous tracts of the host during neurogenesis. Their ability to cross this foreign territory and reach their goal may not necessarily indicate disagreement with the statement by Weiss ("41) that: "... when nerve fibers are seen to move towards a remote destination, one may take it for granted that that goal was instrumental in laying down an oriented pathway in the medium, rather than acting on the fibers directly." However, it is difficult to conceive of an ultrastructural framework with a bilaterally symmetrical organization being entered by additional fiber tracts from abnormal positions without having these tracts meet with considerable mechanical resistance.

According to Weiss ('41, '47, '50), the outgrowing nerve fiber elongates by amoeboid movement of the protoplasmic tip, and many such protrusions, some so thin that they are invisible with ordinary microscopy, may be elaborated by a single neuron. He has shown that in regeneration of peripheral nerves these numerous fibers may grow randomly unless oriented by the substrate, but when a "pioneering" fiber reaches 
its proper terminus, it expands and other fibers grow out along it. Piatt ('48) states that there is evidence that ingrowing cranial nerves are directed to particular parts of the brain wall by forces which may be related to functional homogeneity of nerve and brain centers. The present observations suggest that central neurons may act in a similar fashion, sending out pioneering fibers which may grow more or less at random and seek out corresponding cells with which they have a biochemically specified complementary affinity.

The ability to accept supernumerary sense organs or brain parts, the apparent reversal of symmetry of implanted brain, and the dependent differentiation of lower brain centers indicate great plasticity in the organization of the central nervous system during neurogenesis.

SUMMARY

1. In order to study the orientation of anomalous nerve tracts within the brain and their ability to establish functional synaptic connections with brain centers of the host during neurogenesis, 180 median eye implantations were made in $R$. pipiens embryos at Shumway stage 17. Twenty-six were serially sectioned, and of these, 23 had formed extensive neural connections between the grafted neural tissue and the brain of the host.

2. Five specimens which demonstrated that functional sensory-motor relationships existed between the implants and the host brains are described. Two of these showed synchronous movements of the implanted and normal eyes, two showed vestibular reflexes, and one showed definite visuomotor responses of the host, mediated by the implanted eye.

3. Morphological and behavioral evidence of functional integration between the graft and the host brain of the specimen showing visuomotor responses is discussed in detail. This evidence includes optokinetic response tests of visual perception by the implanted eye, photophobia, forced circling activity, and the differentiation of a supernumerary Mauthner's cell in the medulla of the host. 
4. Experimental results and morphological evidence suggest that axonal protrusions of central neurons may actively seek out complementary cells and may influence the differentiation of lower brain centers.

\section{LITERATURE CITED}

Burch, A. B. 1942 A mierosealpel for use in experimental embryology. Seience, $96: 387-388$.

BURR, H. S. 1916 Regeneration in the brain of Amblystoma (embryos). J. Comp. Neur., 26: 203-211.

1932 An electrodynamic theory of development suggested by studies of proliferation rates in the brain of Amblystoma. Ibid., 56: $347-371$.

1958 Design in the nerrous system. Anat. Rec., 131: 405-415.

Detwiler, S. R. 1929 Some observations upon grafted eyes of frog larvae. Arch. f. Entw-mech., 116: 555-566. 1936 Neuroembryology. Macmillan Co., N. Y.

DETwiler, S. R., AND R. H. vAN DYKE 1935 Further observations upon abnormal growth responses of spinal nerves in Amblystoma embryos. J. Exp. Zool., 69: 137-164.

Dragomirow, N. 1933 Über Koordination der Teilprozesse in der embryonalen Morphogenese des Augenbechers. Arch. f. Entw-mech., 129: 522-560.

GreenE, W. F. 1947 Histogenesis of Mauthner's neurone in Amblystoma. Anat. Rec., $97: 389$.

HARRISON, R. G. 1907a Observations on the living developing nerve fiber. Ibid., 1: $116-118$.

$1907 \mathrm{~b}$ Experiments in transplanting limbs and their bearing upon the problems of the development of nerves. J. Exp. Zool., 4: 239-281.

Herrick, C. J. 1948 The Brain of the Tiger Salamander. The University Press, Chicago.

KAPPERS, C. U. 1917 Further contributions on neurobiotaxis. IX. An attempt to compare the phenomena of neurobiotaxis with other phenomena of taxis and tropism. The dynamic polarization of the neurone. J. Comp. Neur., 27: 261-298.

Kappers, C. U., G. C. Huber and E. C. Crosex 1936 The Comparative Anatomy of the Nervous System of Vertebrates. Macmillan Co., N. Y.

KING, H. D. 1905 Experimental studies on the eye of the frog embryo. Arch. f. Entw.-mech., 19: 85-107.

LEwIS, W. H. 1905 Experimental studies on the development of the eye in Amphibia. J. Exp. Zool., 2: 431-445.

1907 Experiments on the origin and differentiation of the optic vesicle in Amphibia. Am. J. Anat., 7: 259-277.

MatThey, R. 1926 La greffe de l'oeil. Étude experimentale de la greffe de l'oeil chez le Triton. Arch. f. Entw.-mech., 109: 326-341. 
MAY, R. M. 1927 Modifications des centres nerveux dues à la transplantation de l'oeil et de l'organe olfactif chez les embryons d'Anoures. Arch. de Biol., 37 : 335-396.

NIOHOLAs, J. S. 1933 The correlation of movement and nerve supply in transplanted limbs of Amblystoma. J. Comp. Neur., 57: 253-283.

NIEUWKoop, P. D. 1952 Activation and organization of the central nervous system in amphibians. I. Induction and activation. II. Differentiation and organization. III. Synthesis of a new working hypothesis. $J$. Exp. Zool., 120: 1-29, 33-80, 83-106.

OPPENHEIMER, J. M. 1941 The anatomical relationships of abnormally located Mauthner's cells in Fundulus embryos. J. Comp. Neur., 74: 131-167.

Piats, J. 1947 A study of the factors controlling the differentiation of Mauthner's cell in Amblystoma. Ibid.. 86: 199-235.

1948 Form and causality in neurcgenesis. Biol. Rev., 23: 1-45.

SPERRY, R. W. 1942 Reestablishment of visuomotor coordination by optic nerve regeneration. Anat. Rec., 81: 470.

$1943 a$ Visuomotor coordination in the newt (Trituris viridescens) after regeneration of the optic nerve. J. Comp. Neur., 79: 33-55.

$1943 \mathrm{~b}$ Effect of 180 degree rotation of the retinal field on visuomotor coordination. J. Exp. Zool., 92: 263-279.

$1943 \mathrm{c}$ Functional results of erossing sensory nerves in the rat. $J$. Comp. Neur., 78: 59-90.

1944 Optic nerve regeneration with return of vision in anurans. J. Neurophysiol., 7 : 57-69.

1945a Horizontal intracortical organization in the cerebral control of limb movement. Proc. Soc. Exp. Biol. Med., 60: 78.

1945b The problem of central nervous reintegration after nerve regeneration and muscle transposition. Quart. Rev. Biol., 20: 311-369.

$1945 \mathrm{c}$ Restoration of vision after cross-union of optic nerves and after contralateral transplantation of eye. J. Neurophysiol., 8: 15-28.

1945 d Centripetal regeneration of the 8 th cranial nerve root with systematic restoration of vestibular reflexes. Am. J. Physiol,, 144: 735-741.

1948a Orderly patterning of synaptic associations in regeneration of intracentral fiber tracts mediating visuomotor coordination. Anat. Rec., 10\%: 63-75.

$1948 \mathrm{~b}$ Patterning of central synapses in regeneration of the optic nerve in teleosts. Physiol. Zool, 21: 351-361.

1949 Reimplantation of eyes in fishes (Bathygobius soporator) with recovery of vision. Proc. Soc. Exp. Biol. Med., 71: 80-81.

1955 Problems in the biochemical specification of neurons. In: Biochemistry of the Developing Nervous System, H. Waelsch, ed. Academic Press, N. Y., pp. 78-84.

Stefarell, A. 1951 The Mauthnerian apparatus in the Tchthyopsida; its nature and function and correlated problems of neurohistogenesis. Quart. Rev. Biol., 26: 17-34. 
Stone, L. S. 1930 Heteroplastic transplantation of eyes between the larvae of two species of Amblystoma. J. Exp. Zool., 55: 193-261.

1942 Transplantations of the salamander eye four times showing return of vision after each operation. Anat. Rec., 8\%: 494.

1944 Functional polarization in retinal development and its reestablishment in regenerating retinae of rotated grafted eyes. Proc. Soe. Exp. Biol. Med., 5r: 13-14.

1948 a Funetional polarization in developing and regenerating retinae of transplanted eyes. Ann. N. Y. Acad. Sei., 49: 856-864.

$1948 \mathrm{~b}$ Experiments on return of vision in transplanted eyes of salamanders. Anat. Rec., 101: 697-698.

1950 Neural retina degeneration followed by regeneration from surviving retinal pigment cells in grafted adult salamander eyes. Ibid., 106: 89-109.

Stone, L. S., AND I. ZAUR 1940 Reimplantation and transplantation of adult eyes in the salamander (Triturus viridescens) with return of vision. J. Exp. Zool., 85: 243-269.

Stoppani, A. O. M. 1942 Neuroendocrine mechanism of color change in Bufo arenarum Hensel. Endocrinology, 30: 782-786.

Twitry, V. C. 1955 Eye. In: Analysis of Development. B. H. Willier, P. A. Weiss, V. Hamburger, eds. W. B. Saunders Co., Philadelphia, pp. $402-414$.

Uhlenfuth, E. 1912 Die Transplantation des Amphibienauges. Areh. $f$. Entw.-meeh., 33: 723-747.

Wriss, P. 1934 In vitro experiments on the factors determining the course of the ontgrowing nerve fiber. J. Exp. Zool., 68: 393-448.

1936 Selectivity controlling the central-peripheral relations in the nervous system. Biol. Rev., 11: 494-531.

1937 Further experimental investigations on the phenomenon of homologous response in transplanted amphibian limbs: II. Nerve regeneration and the innervation of the transplanted limbs. J. Comp. Neuro., 66: 481-535.

1941 Nerve patterns. The mechanism of nerve growth. Growth (Suppl.), 5: 163-203.

1945 Experiments on cell and axon orientation in vitro: the role of colloidal exudates in tissue organization. J. Exp. Zool., 100: 353-386.

1947 The problem of specificity in growth and development. Yale J. Biol. Med., 19: 235-278.

1950 The deplantation of fragments of nervous system in amphibians. I. Central reorganization and the formation of nerves. J. Exp. Zool., 113 : 397-462.

1952 "Attraction fields" between growing tissue cultures. Science, 115: 293-295.

1958 Cell contact. Int. Rev. Cytol., 7: 391-423.

YNTEMA, C. L. 1955 Ear and nose. In: Analysis of Development. B. H. Willier, P. A. Weiss, v. Hamburger, eds. W. B. Saunders Co., Philadelphia, pp. 415-428. 


\section{PLATES}


PLATE 1

EXPLANATION OF FIGURES

1 Dorsal view of an experimental tadpole with three eyes. $\times 5$.

2 Optic nerve fibers from the implanted and normal eyes mingling in the optie chiasma of tadpole IX. $\times 85$.

3 and 4 Intermingling of nerve fibers of the grafted brain and medulla of specimen VR-2. Note fibers of the auditory nerve root ascending toward the graft. Figure $3 \times 30$. Figure $4 \times 65$.

5 Section through the diencephalon of specimen OR-1 showing symmetry of implant and host brain. $\times 30$.

6 Section through the diencephalon of tadpole $34 . \times 30$.

7 Section through the meseneephalon of specimen OR-1 showing the optic ventricle formed by joining of the optie lobe of the implant with that of the right side of the host's brain. $\times 30$.

8 Close-up of the mesencephalon of OR-1 showing nerve fibers crossing the area of fusion of the implanted and host brain. $\times 70$. 

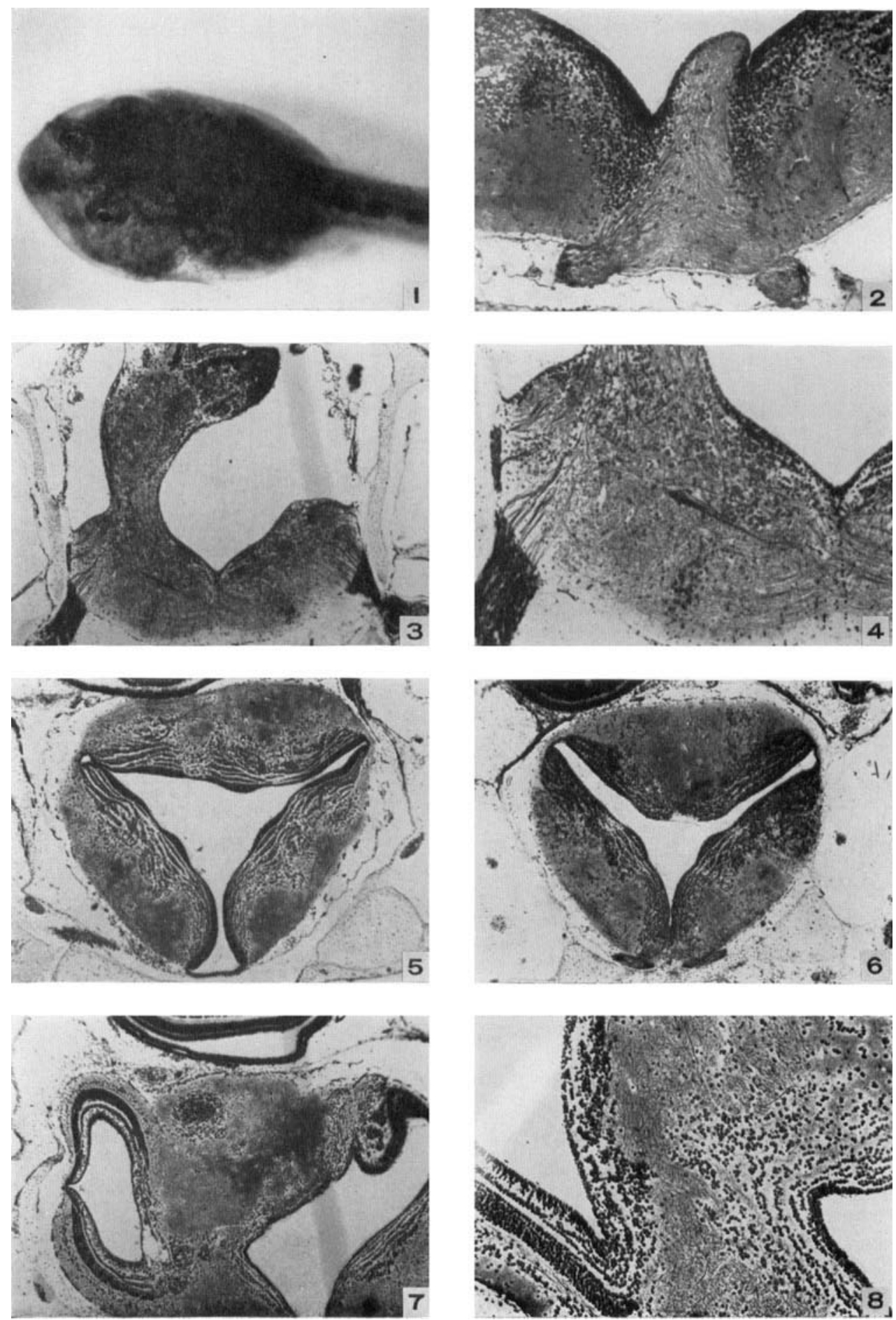


\section{PLATE 2}

RXPLANATION OF FIGURES

9 Drawing of tadpole OR-1. The implanted eye and host's normal left eye are shown.

10 Giant Mauthner's cell in the medulla of a $R$. pipiens tadpole. $\times 550$.

11 Three Mauthner's cell axons in the median longitudinal faseicles of tadpole OR-1. $\times 155$.

12 Graphic reconstrulction of a normal brain.

13 Graphic reconstruction of the brain and eyes of specimen IX. 
EMERSON HIBBARD
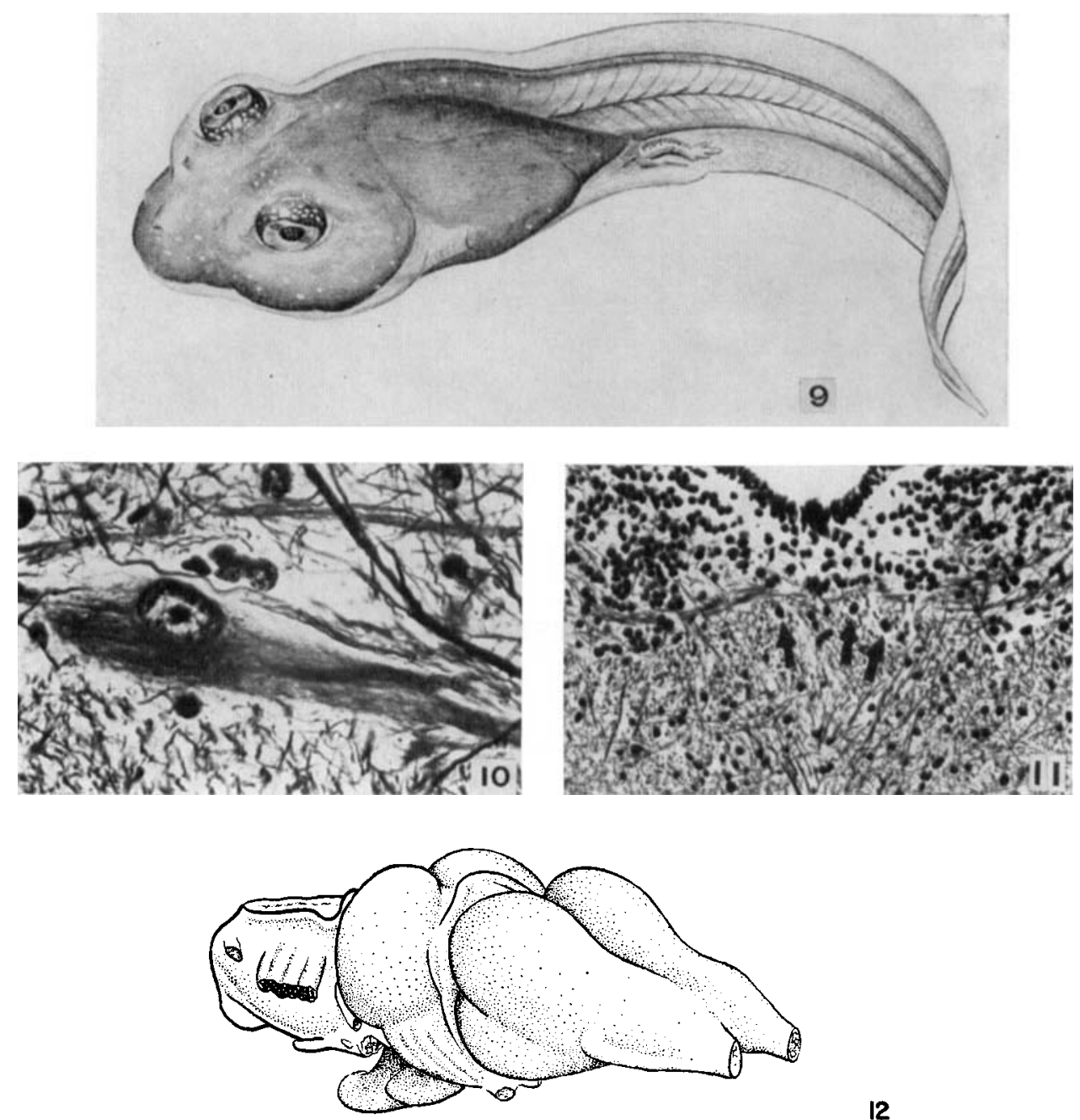

12

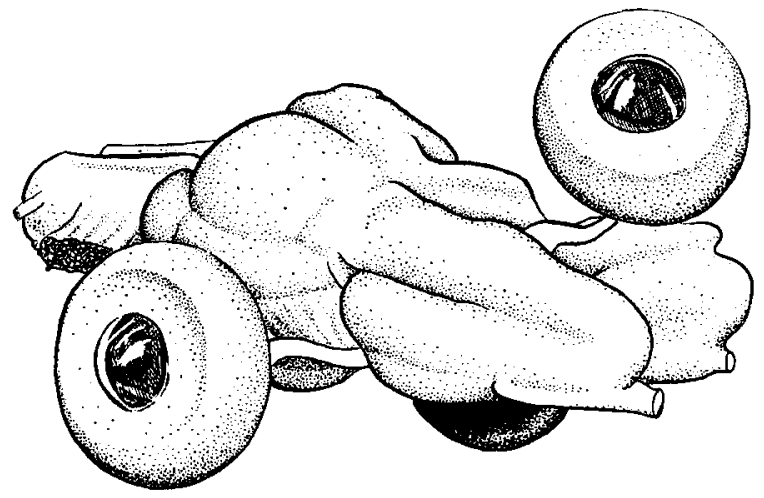




\section{PLATE 3}

\section{EXPLANATION OF FIGURES}

14 Graphie reconstruction of the brain and eyes of specimen oR-1 showing severed optic nerves of the normal eyes.

15 Diagram illustrating the proposed relationships between the optic nerve fibers (O.T.), the tectobulbar tracts (T-B.), and Mauthner's axons (M.A.) of tadpole $\mathrm{OR}-1$. 

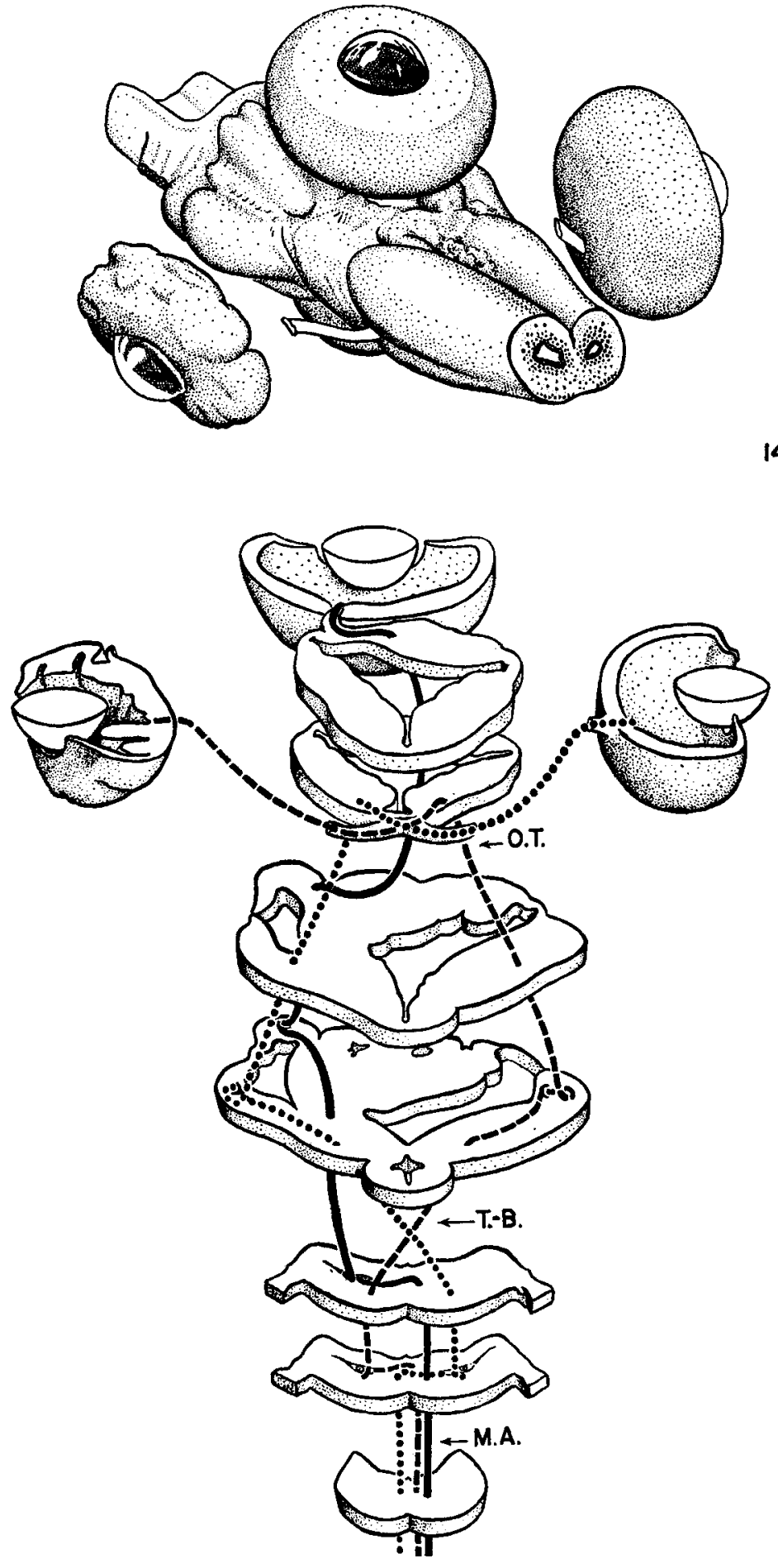